\title{
Application of Analytical Hierarchy Process (AHP) Method as Decision Support in Determining Internet Service Providers
}

\author{
Septy Nur Aulia Darmantya \\ Telkom University; \\ Email: septydarmantya@student.telkomuniversity.ac.id
}

\begin{abstract}
Internet service providers that are used today are growing rapidly with various advantages and disadvantages. Because of this, there are many criteria that can be used as basic internet service providers that are most suitable for use. In this study, the author raised several network providers namely Telkomsel and Indosat. To choose a good Internet service provider is by using an AHP (Analytical Hierarchy Process) method, with this method respondents are guided to make decisions based on two-level criteria. Level 1 criteria: data transfer speed, type of service, and type of card. While for level 2 there are three alternatives, namely Telkomsel and Indosat. From the results of the selection of internet service providers, Telkomsel is the best compared to Indosat.
\end{abstract}

Keywords: AHP, Internet Service Provider, Decision Making, Operation Research

\section{Introduction}

\subsection{Explanation of the object study}

ISP (Internet Service Provider), an institution or company that connects a user's computer with the internet [1]. In general, the internet is a technology that has very rapid development and is a symbol of how to communicate freely, without being limited by space, distance, and time. Supported by the advantages possessed by the internet, including being able to connections that are relatively affordable and the availability of unlimited information, the internet has now become the main alternative to meet all needs, especially the need for information and education that will provide a positive value for all activities.

However, there have been many internet services that can be used to help facilitate users in accessing the internet. Many conveniences and advantages they offer. Internet service itself is a relationship between various types of computers and networks in the different world operating systems and applications where the relationship utilizes the advancement of communication media (telephone and satellite) that uses standard communication protocols, namely the TCP / IP protocol containing information [1].

There are several network providers that can be selected for internet use, namely: XL, Telkomsel, and IM3. The three alternative internet networks each have their strengths and weaknesses. In order to develop the internet network, the process of selecting the right provider is important. Therefore, the authors use AHP (Analytical Hierarchy Process) to support decision making in choosing the best internet service provider.

\subsection{Prior Research}

Some researchers have used AHP (Analytical Hierarchy Process) in decision making. Some of the research is widespread in various fields, ranging from decision making about business, economics, and others [2] [3] [4] [5]. This can provide evidence that the AHP method is a method that needs to be utilized for other forms of problems, one of which is in selecting the 
best Internet Service Provider to use. Because there is no single research that addresses this in detail.

This research tries to illustrate how to use AHP in choosing the best Internet Services Provider to use. It is hoped that after reading the illustrations presented and explained in this paper, it will be easier to understand what AHP is and how it is applied in selecting the best Internet Service Provider to use.

\section{Brief Description of Methods}

AHP (Analytical Hierarchy Process) is a decision support method developed by an Iraq-born University of Pittsburgh mathematics professor, Thomas L. Saaty. In the Analytical Hierarchy Process, a respondent is asked to make a decision based on the comparison. Before making the decision, the first stage is to make a decision-making hierarchy.

The decision-making hierarchy is usually through two levels, at level-1 which is about the comparison of criteria and at level-2, which is the comparison of alternatives based on these criteria. At level-1, comparison of criteria. A respondent is asked to determine which criteria are most important in making a decision. In a comparison of these criteria, all the criteria used are involved in the comparison in pairs. Number 4 shows the highest level of importance. Meanwhile, 1/4 shows the lowest level of importance.

After doing a comparison of each criterion. The next step is to make comparisons of alternative decisions based on each criterion. At this stage, it is actually the same as the criteria comparison stage. Between each alternative that is compared in pairs. The comparison can be done as many times as the number of criteria involved. So, in making alternative comparisons requires more comparison processes compared with comparison criteria.

The last step is to do a summary and assessment in the comparison carried out so that you will get a calculation result. And the results of these calculations contain decisions on which criteria are more important than the other criteria, which alternatives are better based on each criterion, and which alternatives are best based on all criteria.

Besides the main calculation in choosing the best alternative to the AHP method, a consistency calculation must also be done. This consistency test needs to be done because when the respondent makes comparisons on many criteria simultaneously, inconsistently the values will be ordered from the most important to the least important.

\section{Calculation Process}

The first stage of the calculation is to create a hierarchical structure. The process of compiling this hierarchy needs to go through the process of studying literature to find out what criteria are relevant influences on the decision-making process. In this paper we assume that the literature study process has been carried out so that we get a hierarchical structure like the following: 


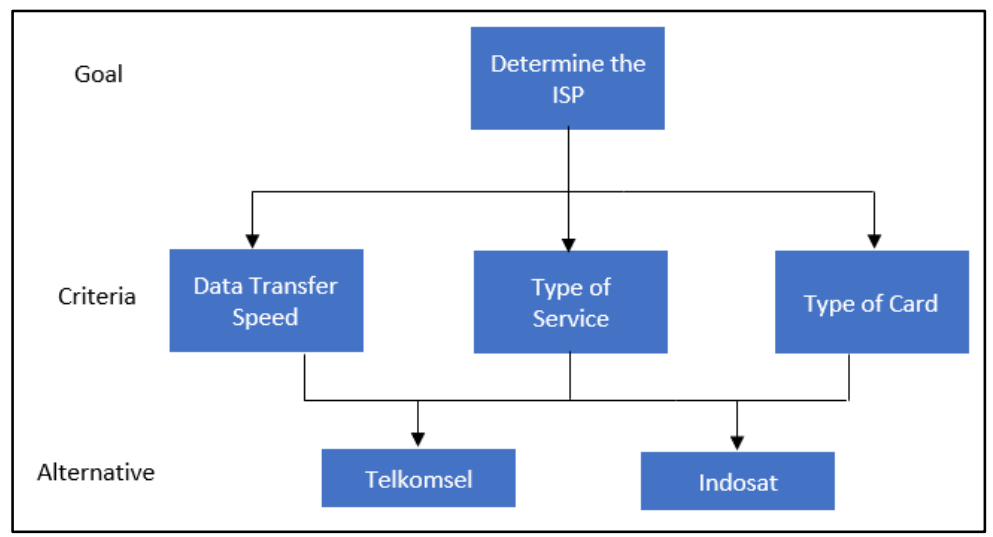

Figure 1 Hierarchical Structure

In figure 1 is the hierarchical structure in this case. Criteria in the selection are data transfer speed, type of service, and type of card. While alternative decisions are Telkomsel and Indosat. The next step is to make comparisons using a pairwise comparison matrix. Here we show in table 1 the dummy values for pairwise comparison matrices.

Table 1 Comparison Matrix

\begin{tabular}{|c|c|c|c|}
\hline CRITERIA & $\begin{array}{c}\text { Data Transfer } \\
\text { Speed }\end{array}$ & $\begin{array}{c}\text { Type of } \\
\text { Service }\end{array}$ & $\begin{array}{c}\text { Type of } \\
\text { Card }\end{array}$ \\
\hline Data Transfer Speed & 1,000 & 0,109 & 0,204 \\
\hline Type of Service & 9,200 & 1,000 & 1,300 \\
\hline Type of Card & 4,900 & 0,769 & 1,000 \\
\hline Total & 15,100 & 1,878 & 2,504 \\
\hline
\end{tabular}

After making the comparison matrix, the next step is to calculate the Priority Vector as contained in table 2:

Table 2 Priority Vector

\begin{tabular}{|c|c|}
\hline \multicolumn{2}{|c|}{ Priority Vector } \\
\hline Data Transfer Speed & 0,069 \\
\hline Type of Service & 0,554 \\
\hline Type of Card & 0,378 \\
\hline
\end{tabular}

After the priority vector is obtained, the next step is Consistent calculation. Consistency Test can be seen in table 3:

Table 3 Consistency Value

\begin{tabular}{|c|c|c|c|c|c|}
\hline $\begin{array}{l}\text { Time } \\
\text { Result }\end{array}$ & $\begin{array}{l}\text { Divided } \\
\text { Result }\end{array}$ & Lambda & $\mathrm{Cl}$ & RI & CR \\
\hline 0,206 & 3,003 & 3,015 & 0,008 & 0,660 & 0,011 \\
\hline 1,675 & 3,026 & & & & \\
\hline 1,140 & 3,016 & & & & \\
\hline
\end{tabular}

In addition to comparing each criterion, it is also necessary to compare each alternative. Because there are three criteria involved, all alternatives are compared using three paired comparison matrix tables where each table is used for each criterion. 
a. Data Transfer Speed

Table 4 Comparison Matrix of Data Transfer Speed

\begin{tabular}{|c|c|c|}
\hline & Telkomsel & Indosat \\
\hline Telkomsel & 1 & 0,25 \\
\hline Indosat & 4 & 1 \\
\hline Total & 5 & 1,25 \\
\hline
\end{tabular}

Table 5 Normalized Matrix and Priority Vector of Data Transfer Speed

\begin{tabular}{|c|c|c|c|c|}
\hline & Telkomsel & Indosat & Total & $\begin{array}{c}\text { Priority } \\
\text { Vector }\end{array}$ \\
\hline Telkomsel & 0,2 & 0,2 & 0,400 & 0,200 \\
\hline Indosat & 0,8 & 0,8 & 1,600 & 0,800 \\
\hline Total & 1 & 1 & 2,000 & \multicolumn{1}{|c}{} \\
\cline { 1 - 3 } & &
\end{tabular}

b. Type of Service

Table 6 Comparison Matrix of Type of Service
\begin{tabular}{|c|r|r|}
\hline & Telkomsel & Indosat \\
\hline Telkomsel & 1 & 9 \\
\hline Indosat & 0,111 & 1 \\
\hline Total & 1,111 & 10 \\
\hline
\end{tabular}

Table 7 Normalized Matrix and Priority Vector of Type of Service

\begin{tabular}{|c|r|r|r|r|}
\hline & Telkomsel & Indosat & Total & $\begin{array}{c}\text { Priority } \\
\text { Vector }\end{array}$ \\
\hline Telkomsel & 0,9 & 0,9 & 1,800 & 0,900 \\
\hline Indosat & 0,1 & 0,1 & 0,200 & 0,100 \\
\hline Total & 1 & 1 & 2,000 & \multicolumn{1}{|c}{} \\
\cline { 1 - 3 } & & \multicolumn{3}{|c|}{}
\end{tabular}

c. Type of Card

Table 8 Comparison Matrix of Type of Card
\begin{tabular}{|c|r|r|}
\hline & Telkomsel & \multicolumn{1}{|c|}{ Indosat } \\
\hline Telkomsel & 1 & 0,333 \\
\hline Indosat & 3 & 1 \\
\hline Total & 4 & 1,333 \\
\hline
\end{tabular}

Table 9 Normalized Matrix and Priority Vector of Type of Card

\begin{tabular}{|c|r|r|r|r|}
\hline & Telkomsel & Indosat & Total & $\begin{array}{c}\text { Priority } \\
\text { Vector }\end{array}$ \\
\hline Telkomsel & 0,25 & 0,25 & 0,500 & 0,250 \\
\hline Indosat & 0,75 & 0,75 & 1,500 & 0,750 \\
\hline Total & 1 & 1 & 2,000 & \multicolumn{1}{|c}{} \\
\cline { 1 - 3 } & &
\end{tabular}

The last step is determining the best alternative based on the criteria, along with the priority vector, and the priority vector for each alternative. The results of these calculations can be seen in table 4 . 
Table 10 Calculation Priority Ranking

\begin{tabular}{|c|c|c|c|c|}
\hline & Data Transfer Speed & Type of Service & Type of Card & Priority \\
\cline { 2 - 4 } & 0,069 & 0,554 & 0,378 & Ranking \\
\hline Telkomsel & 0,200 & 0,900 & 0,250 & 0,606 \\
\hline Indosat & 0,800 & 0,100 & 0,750 & 0,394 \\
\hline
\end{tabular}

Based on the calculation using the AHP method, it was found that the best alternative for an Internet Service Provider is Telkomsel. In the first criteria, Indosat is better than Telkomsel. For the second criterion, Telkomsel is better than Indosat. Whereas for the third criterion Indosat is better than Telkomsel. However, it turns out that the second criterion is higher in priority than the first criterion. So, in this case, overall Telkomsel is better even though Indosat also excels in other aspects.

\section{Penutup}

4.1. Conclusion

Based on the description and arrangement of criteria and alternatives formed by the Analytical Hierarchy Process (AHP) method, formed from 3 criteria and 2 alternatives. Through this method, respondents are asked to determine criteria and alternatives so that they can calculate themselves from various criteria and alternatives, which one has the best priority value.

So, from the calculations using the AHP method, it is obtained the best Internet Service Provider that can be used based on 3 selected criteria is Telkomsel. Because the calculation of Telkomsel which has the best Priority Ranking value compared to Indosat.

\subsection{Suggestion}

For the development of subsequent research is the use of other methods for making a decision. In addition, a study can be done in advance about the criteria related to the decision-making process.

\section{References}

[1] Chen, C.-F., 2006. Applying the Analytical Hierarchy Process (AHP) Approach to Convention Site Selection. Journal of Travel Research.

[2] Kayastha, P., Dhital, M. \& De Smedt, F., 2013. Application of the analytical hierarchy process (AHP) for landslide susceptibility mapping: A case study from the Tinau watershed, west Nepal. Computer and Geosciences, Volume 52, pp. 398-408.

[3] Mahdi, I. M. \& Alreshaid, K., 2005. Decision support system for selecting the proper project delivery method using analytical hierarchy process (AHP). International Journal of Project Management, October, 23(7), pp. 564-572.

[4] Rahman, P. A., 2017. The reliability model of the fault-tolerant border routing with two Internet services providers in the enterprise computer network. Journal of Physics: Conference Series.

[5] Thanki, S., Govindan, K. \& Thakkar, J., 2016. An investigation on lean-green implementation practices in Indian SMEs using analytical hierarchy process (AHP) approach. Journal of Cleaner Production, Volume 135, pp. 284-298. 